\title{
ANALISE DE TRILHA PARA CARACTERES MORFOLÓGICOS DO FEIJÃO-BRAVO (CAPPARIS FLEXUOSA) NO CARIRI PARAIBANO*
}

\author{
PATH ANALYSIS OF MORPHOLOGIC CHARACTERS OF "FEIJÃO-BRAVO" (CAPPARIS \\ FLEXUOSA) IN THE CARIRI REGION OF PARAIBA STATE - BRAZIL
}

Silva, M.A. ${ }^{1}$, D.S. Silva ${ }^{2 a}$, L.A. Andrade ${ }^{2}$, W.B. Lopes $^{2 b}$ e G.R.A. Santos ${ }^{3}$

1 UFRPE. Rua Dom Manoel de Medeiros s/n. Dois Irmãos. Recife-PE, 52171-900. Brasil. monica.zte@gmail.com ${ }^{2}$ Universidade Federal da Paraíba. Areia-PB. CEP 58397-000. Brasil. adivan@ufpb.cca.br; bweds.jpa@neoline.com.br

${ }^{3}$ Instituto Agronômico de Pernambuco/IPA. Recife-PE. Brasil. gladstonrafael@ipa.br

\section{PALAVRAS CHAVE ADICIONAIS}

Forrageira nativa. Caatinga. Correlação. Número de folha.

\section{RESUMO}

O objetivo deste trabalho consistiu em obter estimativas do desdobramento das correlações em análise de trilha sobre as variáveis, número de brotações, diâmetro do caule, comprimento do caule e número de folhas de plantas de feijãobravo em dois períodos de avaliação em condições edafoclimaticas do Cariri Paraibano. As características número de brotações na época seca e comprimento do caule na época chuvosa foram capazes de explicar melhor o desenvolvimento do numero de folhas, atuando de forma direta e inversamente proporcional sobre a variável básica. $\mathrm{O}$ estudo permitiu concluir que o número de brotações exerce grande influência no número de folhas em ambos os períodos de avaliação.

\section{SUMMARY}

This work aimed to estimate correlation coefficients path analysis. It was studied the effect of the tiller number, stem diameter, stem length and leaf number of Capparis flexuosa plants during two evaluation periods in the Cariri region of Paraiba State, Brazil. Tiller number during the dry season and stem length during the rainy season explained best the leaf number, acting respectively in a direct and inversely proportional way on the main variable, changing according to the environmental conditions during the growth

*Projeto financiado pelo CNPq.

Recibido:16-1-07. Aceptado: 8-2-07.

\section{AdDitional KeYWORDS}

Native forage. Caatinga. Correlation. Leaf number.

period. The results allowed the conclusion that tiller number exerts great influence on leaf number in both evaluation periods.

\section{INTRODUÇÃO}

O conhecimento das relações existentes entre as variáveis empregadas para a avaliação de espécies forrageiras nativas é de suma importância, uma vez que pouco se conhece sobre o assunto. A importância da correlação entre caracteres no estudo de plantas reside no fato de se poder avaliar o quanto da alteração de um caráter pode afetar os demais no decurso do crescimento da espécie. A magnitude e valor das correlações, contudo, não são suficientes para esclarecer as relações entre as variáveis estudadas. É nesse contex to que se percebe a aplicabilidade da análise de trilha, uma vez que se permite o desdobramento das correlações simples entre os caracteres nos seus efeitos diretos e indiretos (Santos et al., 2000).

Está técnica tem sido amplamente utilizada no estudo de diversas culturas (Cargnelutti Filho et al., 2004; Furtado et al., 2002 e Carvalho et al.,1999). Entretanto, ainda são escassos trabalhos dessa

Arch. Zootec. 58 (221): 121-124. 2009. 
natureza envolvendo forrageiras nativas. No feijão bravo (Capparis flexuosa L.), os estudos ainda são restritos, entretanto, por ser esta uma Caparacea que possui sistema de resistência a seca peculiar à sua espécie, o conhecimento da inter-relação entre os caracteres morfológicos torna-se de grande importância para que se possa conduzir com sucesso um estudo mais aprofundado que objetive a elevação conhecimento desta espécie.

Nesse trabalho, objetivou-se aplicar o coeficiente de trilha em plantas de feijãobravo em dois períodos de avaliação, a fim de verificar a influência das variáveis independentes sobre o número de folhas.

\section{MATERIALEMÉTODOS}

O experimento foi conduzido na Fazenda Carnaúbas, município de Taperoá-PB, em uma área de 0,5 ha cultivada com palma forrageira (Opuntia ficcus indica) consorciada com feijão bravo (Capparis flexuosa), onde foram selecionadas 30 plantas de feijãobravo. Esta região se caracteriza por um clima seco, com precipitações pluviométricas irregulares (400 mm anuais), foram consideradas duas épocas de avaliação: época seca de setembro de 2000 a fevereiro de 2001 e época chuvosa de março a julho de 2001.

As características avaliadas foram números de folha (NF) (variável dependente principal ou básica) e as variáveis independentes explicativas número de brotações (NB), diâmetro do caule (DC) e comprimento do caule (CC). Os resultados da análise de trilha foram interpretados conforme Singh et al.,1969, em que, basicamente, i) coeficientes de correlação e efeitos diretos altos indicam que estas variáveis independentes explicam grande parte da variação da variável básica e que ii) coeficientes de correlação positivos (ou negativos), mas o efeito direto é de sinal diferente, variáveis com maiores efeitos indiretos devem ser consideradas simultaneamente para explicarem a variação da variável básica.
Os dados obtidos foram submetidos a análises estatísticas pelo programa computacional Genes (Cruz, 2001).

\section{RESULTADOSEDISCUSSÃO}

O número de brotações no primeiro corte e comprimento do caule no segundo corte, foram as variáveis que apresentaram correlações positivas e significativas com o número de folhas do feijão bravo, demonstrando que essas variáveis possivelmente influenciaram, de algum modo, a expressão dessa característica.

O diâmetro do caule foi a variável que se correlacionou menos com o número de folhas no primeiro corte, já no segundo corte o número de brotações foi o que apresentou menor correlação. Segundo Montardo et al. (2003) a razão para baixa correlação entre variáveis é a ocorrência de pouca variabilidade em uma das mesmas, uma vez que esse tipo de análise procura identificar uma eventual associação na variação das características em estudo.

$\mathrm{O}$ efeito direto do número de brotação no primeiro corte sobre o número de folha foi alto indicando sua verdadeira correlação com essa variável dependente, não sofrendo efeito indireto das variáveis estudadas. É interessante observar que a correlação entre essas duas características se deu praticamente apenas pelo efeito direto da primeira variável sobre a segunda (tabela I). Entretanto o efeito direto do número de brotações no segundo corte sobre o número de folhas foi negativo, indicando que nessa época, essa característica não determinou o aumento do número de folhas, que apesar de sofrer um forte efeito indireto do comprimento do caule, apresentou uma baixa correlação. Possivelmente isso pode ter ocorrido devido à época ser considerada chuvosa, caracterizando o baixo crescimento das plantas. Portanto, para época seca o número de brotações se mostrou como a principal característica na determinação do número de folhas. 
Dos caracteres estudados o diâmetro do caule na época considerada seca foi o que apresentou um dos menores efeitos direto sobre o número de folhas (tabela I), não sofrendo influencia indireta positiva de outros caracteres, exceto do comprimento do caule. Neste caso observa-se que o efeito indireto negativo não apresentou forte influencia no efeito direto do diâmetro do caule. Ao isolar-se os efeitos indiretos do diâmetro do caule têm-se uma baixa correlação, mas de mesmo sentido, desta forma o diâmetro do caule contribui em pequena escala com o número de folhas.

$\mathrm{Na}$ época considerada chuvosa o diâmetro do caule apresentou boa correlação com o número de folhas, entretanto obteve um efeito direto negativo, isso indica a forte influencia das variáveis indiretas sobre esta característica. A correlação positiva entre essas duas variáveis se deu, indiretamente, pelo efeito do comprimento do caule. Em função dos resultados obtidos, verifica-se que o caráter diâmetro do caule com baixa correlação e baixo efeito direto prevê ganho insatisfatório para este estudo. Deste modo, esta característica mostrou pouca importância no aspecto da avaliação entre épocas.

$\mathrm{O}$ efeito direto do comprimento do caule sobre o número de folhas nas duas épocas avaliadas foi alto indicando sua verdadeira correlação com essa variável dependente, sofrendo pouco efeito indireto das variáveis estudadas, exceto na época chuvosa onde os efeitos indiretos apresentaram-se negativos. É interessante observar que a correlação entre essas duas características se deu praticamente apenas pelo efeito direto da primeira variável sobre a segunda (tabela I). Portanto, o comprimento do caule também se mostrou como uma das principais características na determinação do número de folhas, indicando que uma forte pressão de seleção desse caráter irá beneficiar o número de folhas, pois além do efeito direto sobre o número de folhas o comprimento do caule influenciou indiretamente no efeito direto das variáveis, diâmetro do colmo e número de brotações (época chuvosa).

\section{CONCLUSÕES}

Na época seca o número de brotações foi a variável que destacou-se por apresentar uma alta correlação e efeito direto sobre o número de folhas.

$\mathrm{Na}$ época chuvosa o comprimento do caule foi a variável que apresentou uma alta correlação e efeito direto sobre o número de folhas.

Tabela I. Desdobramento da correlação de Pearson em componentes de efeito direto e indiretos envolvendo a variável básica número de folha e as variáveis independentes explicativas. (Unfolding of the Pearson correlation in direct and indirect effect components; leaf number was the main dependent variable the explanatory variable (DC)).

\begin{tabular}{lcccccr}
\hline & NB & $\begin{array}{c}\text { Seca } \\
\text { DC }\end{array}$ & CC & NB & $\begin{array}{c}\text { Chuvosa } \\
\text { DC }\end{array}$ & CC \\
\hline Efeito direto & 0,746 & 0,026 & 0,459 & $-0,503$ & $-0,238$ & 1,264 \\
Efeito indireto & & & & & & $-0,170$ \\
$\quad$ Via NB & - & $-0,034$ & 0,185 & - & $-0,304$ \\
$\quad$ Via DC & $-0,001$ & - & 0,005 & $-0,080$ & - & $-0,156$ \\
$\quad$ Via CC & 0,113 & 0,101 & - & 0,764 & 0,829 & - \\
Pearson & 0,859 & 0,093 & 0,649 & 0,180 & 0,420 & 0,804 \\
\hline
\end{tabular}

$\mathrm{CC}=$ comprimento do caule; $\mathrm{NB}=$ número de brotações; $\mathrm{DC}=$ diâmetro do caule. 


\section{SILVA, SILVA, ANDRADE, LOPESE SANTOS}

\section{BIBLIOGRAFIA}

Cargnelutti Filho, A., S.J.L. Storck e A.D.C. Lucio. 2004. Interferência da variabilidade da população de plantas de milho sobre a população experimental. Ciência Rural, 36: 42-50.

Carvalho, C.G.P, M.F. Oliveira, C.D. Cruze V.W.D. Casali. 1999. Análise de trilha sob multicolinearidade em pimentão. Pesqui. Agropecu. Bras., 34: 603-613.

Cruz, C.D. 2001. Programa Genes-versão Windows: aplicativo computacional em genética e estatística. Universidade Federal de Viçosa Viçosa, MG.

Furtado, M.R., C.D. Cruz, A.A. Cardoso, A.F.D.F. Coelho e L.A. Peternelli. 2002. Análise de trilha do rendimento do feijoeiro e seus componentes primários em monocultivo e em consórcio com a cultura do milho. Ciência Rural, 32: 217-230.

Montardo, D.P., M.D. Agnol, A.F. Crusius e N.R. Paim. 2003. Analise de trilha para rendimento de sementes de trevo vermelho (Trifolium pratense L.). Rev. Bras. Zootecn., 32: 1076-1082.

Santos, R.C., L.P. Carvalho e V.F. Santos. 2000 Análise de coeficiente de trilha para os componentes de produção do amendoim. Ciência Agrotec., 24: 13-16.

Singh, K.B. and P.D. Mehndiratta. 1969. Genetic variability and correlation studies in cowpea. Indian J. Genet. PI. Br., 30: 104-109.

Archivos de zootecnia vol. 58, núm. 221, p. 124. 